\section{Measuring Soil Water Content: A Review}

\author{
Marco Bittelli ${ }^{1}$
}

AdDiTIONAL INDEX WORDs. experimental methods, water management, sensors, spatial scales

SUMMARY. Soil water content (SWC) is a soil property that plays a crucial role in a large variety of biophysical processes, such as seed germination, plant growth, and plant nutrition. SWC affects water infiltration, redistribution, percolation, evaporation, and plant transpiration. Indeed, the quantification of SWC is necessary for a variety of important applications in horticultural systems, such as optimization of irrigation volumes, fertilization, and soil-water-budget computations. In recent decades, a substantial number of different experimental methods have been developed to determine the SWC, and a large body of knowledge is now available on theory and applications. In this review, the main techniques used to determine the SWC are discussed, first by describing the physical principles behind the most popular methods and then by addressing how the various spatial scales might affect the different methodologies when applied.

S oil water content has an important impact on many fundamental biophysical processes. It affects the germination of seeds, plant growth and nutrition, microbial decomposition of the soil organic matter, nutrient transformations in the root zone, as well as heat and water transfer at the land-atmosphere interface. The quantification of SWC is necessary for different applications, ranging from large-scale calibration of global-scale climate models to field monitoring in agricultural and horticultural systems. In the former, knowledge of SWC is involved in the partitioning of solar radiation into latent and sensible heat, whereas in the latter, SWC measurements help optimize irrigation volumes and schedule, as well as plant nutrition. SWC is also a key variable in determining the rate of decomposition of the soil organic matter, which can affect, for example, the rate of soil respiration and soil carbon sequestration. Moreover, SWC plays a key role in the physicochemical transformation of fundamental nutrients (e.g., nitrogen), such as mineralization, volatilization, and nitrification.

Department of AgroEnvironmental Science and Technology, University of Bologna, Viale Fanin 44, 40125 Bologna, Italy

This paper was part of the workshop "Improvement in Nitrogen and Water Use Efficiency: Interest of Assessment Tools" held 16 Sept. 2008 at the European Society for Agronomy Congress, Bologna, Italy.

The author of this review does not endorse any specific producer of sensors or soil water content measurement devices and is not beholden financially to any private sector support.

${ }^{1}$ Corresponding author. E-mail: marco.bittelli@unibo.it.
In recent decades, a variety of methodologies to measure SWC at different scales have been developed, which has greatly expanded the information available on theory and applications. Since there are a range of techniques based on different physical principles and a variety of available sensors, this review is not intended to provide an exhaustive scientific description of each method, but rather to provide guidance for field scientists and practitioners who are interested in measuring SWC. Specifically, my objective is to provide information and bibliographical sources that might help match the project objectives with the appropriate measurement method. Because of the multitude of private manufacturers developing and selling sensors, specific companies are not listed in the discussion. However, I have provided bibliographical and website references where it is possible to read reviews and comparisons of the various sensors and manufacturers available on the market today.

In this review, the physical principles behind the different methods are described first, followed by the methodologies and sensors employed at different spatial scales. Four main scales of measurements will be described: 1) local scale, 2) field scale, 3 ) catchment scale, and 4) regional and global scale. Clearly, the transitions from one scale to another are not abrupt, and intermediate scale measurements could be added to this simplified classification; however, the spatial-scale approach is useful to better describe and classify the available techniques and their applications.

\section{Physical principles}

Soil water content can be measured directly or indirectly. In the first case, the amount of water is directly measured, for instance, by measuring its weight as a fraction of the total soil weight (gravimetric method). However, this measurement method usually is destructive since the soil sample is removed from the field to be analyzed in the laboratory. Moreover, it is a time-consuming and impractical way of measuring SWC in the field. Because of these limitations, a variety of indirect measurements (also called surrogate methods) have been developed.

An indirect method measures another variable that is affected by the amount of soil water, and then it relates the changes of this variable to the changes in SWC, through physically based or empirical relationships called calibration curves. For instance, the dielectric sensors exploit the changes in soil dielectric properties as function of SWC; the heat dissipation and heat flux sensors use the changes in the soil thermal properties; the neutron scattering technique is based on the loss of high-energy neutrons as they collide with other atoms, in particular hydrogen contained in the water molecule. Although the direct gravimetric method is the reference method for SWC measurement (and commonly used for indirect methods

\begin{tabular}{llll}
\hline $\begin{array}{l}\text { Units } \\
\text { To convert U.S. to SI, } \\
\text { multiply by }\end{array}$ & U.S. unit & SI unit & $\begin{array}{l}\text { To convert SI to U.S., } \\
\text { multiply by }\end{array}$ \\
\hline 38.6807 & $\mathrm{fl} \mathrm{oz} / \mathrm{yard}^{3}$ & $\mathrm{~mL} \cdot \mathrm{m}^{-3}$ & 0.0259 \\
0.3048 & $\mathrm{ft}$ & $\mathrm{m}$ & 3.2808 \\
0.0929 & $\mathrm{ft}^{2}$ & $\mathrm{~m}^{2}$ & 10.7639 \\
0.0283 & $\mathrm{ft}^{3}$ & $\mathrm{~m}^{3}$ & 35.3147 \\
2.54 & inch(es) & $\mathrm{cm}^{3}$ & 0.3937 \\
1.6093 & mile $(\mathrm{s})$ & $\mathrm{km}$ & 0.6214 \\
2.5900 & mile & $\mathrm{km}^{2}$ & 0.3861 \\
$\left({ }^{\circ} \mathrm{F}-32\right) \div 1.8$ & ${ }^{\circ} \mathrm{F}$ & ${ }^{\circ} \mathrm{C}$ & $\left(1.8 \times{ }^{\circ} \mathrm{C}\right)+32$
\end{tabular}


calibration), the majority of the commercial sensors are based on indirect methods. Specific descriptions are provided below.

a) Thermogravimetric measurement is a direct method, and it is the reference method for SWC measurement. It is based on the weight measurement of a wet sample before and after oven drying at $105{ }^{\circ} \mathrm{C}$ for $24 \mathrm{~h}$ (Evett et al., 2008). The difference in weight [the weight of liquid water $\left.\left(m_{1}\right)\right]$ is expressed as fraction of the soil solid weight $\left(m_{\mathrm{s}}\right)$, called gravimetric water content $\left(w=m_{\mathrm{l}} / m_{\mathrm{s}}\right)$. This quantity can be expressed as volume fraction, by multiplying the gravimetric water content by the bulk density of the sample and dividing by the density of liquid water, $\theta=w \rho_{b} / \rho_{1}$, where $\rho_{b}$ and $\rho_{l}$ are the soil bulk and water density, respectively. The value of bulk density should be obtained by volumetric and weight measurements of the same sample, which are then used to determine the gravimetric water content. Using bulk density values obtained from tables or from previous measurements should be avoided since SWC and bulk density are properties that vary in space and time. Both error (bias) and imprecision (larger variance) occur when volumetric water content is calculated using an assumed bulk density or one measured elsewhere or at another time (Evett et al., 2008). When the thermogravimetric measurement is performed for calibration of other SWC sensors, it is important to measure the sample bulk density for conversion into the volumetric form since many indirect methods (e.g., the dielectric sensors) provide volumetric measurements of SWC.

b) Dielectric measurement takes advantage of the differences in dielectric permittivity values between different soil phases (solid, liquid, and gas). Liquid water has a dielectric permittivity of $\approx 80$ (depending on temperature, electrolyte solution, and frequency), air has a dielectric permittivity of $\approx 1$, and the solid phase of 4 to 16 (Hallikainen et al., 1985; Wraith and Or, 1999). This contrast makes the dielectric permittivity of soil very sensitive to variation in SWC. The measurement of the bulk dielectric permittivity is then used to obtain the volumetric water content through calibration curves (Roth et al., 1990; Topp et al., 1980).
Although many different electronic devices and experimental techniques are available, all the dielectric sensors exploit the effect of liquid water dielectric permittivity on the bulk soil dielectric properties. Some sensors derive the dielectric permittivity by measuring the travel time of an electromagnetic wave traveling back and forth on the probe, such as time-domain reflectometry (TDR; Robinson et al., 2003), or by measuring the capacitance of the bulk soil. Other sensors measure the dielectric properties of the reflected electromagnetic wave in the frequency domain, to obtain the dielectric properties of the bulk soil. Indeed, important families of sensors used for SWC are the frequency-domain reflectometry and the capacitance sensors, also referred as dielectric sensors or electromagnetic sensors (Evett and Parkin, 2005; Gardner et al., 1998; Robinson et al., 1999, 2003). These sensors measure the dielectric permittivity of the media using capacitance/frequencydomain technology. Some devices are also equipped to measure SWC, soil temperature, and soil electrical conductivity (EC) within the same sensor.

The accurate use of these sensors requires a good understanding of several factors affecting the measurement, such as the geometric properties of the sensors, soil temperature, bulk soil EC, and the electronic features of the different sensors (Bogena et al., 2007; Robinson et al., 2003). Some authors analyzed different dielectric sensors to review their performance and compared them (Blonquist et al., 2005; Evett et al., 2008, 2009). Soil dielectric properties are also used as a basis for measurements of earth soil moisture using ground-penetrating radar (GPR) for measurement of SWC at larger scales (Gerhards et al., 2008; Huisman et al., 2003).

c) Resistivity measurement is based on the principle that soil resistivity is affected by SWC. Usually, a current is transferred into the soil by electrodes, and the value of soil resistivity is then obtained by measuring the changes in voltage. The most common approach is to use fourprobe resistance methods such as the typical Wenner array (Wenner, 1915) or other configurations that allow for insertion of multiple electrodes into the soil to obtain soil tomography (Amer et al., 1994; Samouelian et al.,
2005; Seyfried, 1993). Other new technologies include the automatic resistivity profiling system, where the electrodes are the wheels of a machine pulled on the soil, which allows for rapid tomography of large areas (Dabas, 2006, 2009). Additional resistivity methods are also available, such as the OhmMapper system (Geometrics, San Jose, CA), which uses electrodes that are dragged on the soil surface (Walker and Houser, 2002).

d) Neutron scattering technique also called neutron probe employs high-energy neutrons produced by a radiation source, which collide with soil atoms. Fast neutrons are emitted by a radioactive source. The neutrons lose their energy as they collide with other atoms, in particular hydrogen. Therefore, the neutrons are slowed down and counted. The instrument is equipped with a source of fast neutrons and a detector of slow neutrons. The number of hydrogen atoms in soils changes because of the change in SWC; therefore, the hydrogen content can be calibrated vs. the count of slow neutrons (Hignett and Evett, 2002). According to Evett (2008) a field-calibrated neutron moisture meter is the most accurate and precise indirect method for SWC measurement in the field. These sensors can be placed on the soil surface or as inserted tube for the measurement of the SWC profile.

e) Measurement of soil thermal properties is an indirect method that exploits changes in soil thermal properties due to variation of SWC. The two main techniques are heat dissipation and heat pulse. The heat dissipation technique uses a heat source (usually a heated needle) and temperature sensors (thermocouples or thermistors), immersed into a porous ceramic that equilibrates with the surrounding soil at a given water content. The needle is heated, and the rate of heat dissipation is measured by the temperature sensors. These changes are affected by the thermal conductivity, which depends on the ceramic water content. The thermal conductivity is then obtained through measuring the differential temperature before and after heating (Shiozawa and Campbell, 1990; Young et al., 2008). In the heat flux method, the pulse of heat is applied at one location and its arrival at another location is determined by measuring the soil temperature at 
the other location. The time required for the pulse of heat to travel to the second location is a function of soil thermal conductivity, which is related to water content. The heat dissipation sensors are also used to estimate soil water potential, through calibration of the sensors at specific soil water potentials (Reece, 1996).

Although the techniques described above are the most common ones, other techniques are also developing such as acoustic wave methods (Adamo et al., 2004; Blum et al., 2004; Lu, 2007), optical methods (Selker et al., 2005; Tidwell and Glass, 1994) and gravity measurements (Leiriao et al., 2009).

\section{Water content measurement at different spatial scales}

Determination of SWC can span many orders of magnitude ranging from $0.1 \mathrm{~m}^{2}$, for common local measurements in the field employing in situ sensors (Ferré et al., 1996; Robinson et al., 2003), to 25 to $25,000 \mathrm{~km}^{2}$, for satellite measurements (Wagner et al., 2007a). Since the measurement depth may vary from technique to technique, SWC determinations are usually expressed as volumetric measurements. But here, for simplicity, units of an area are used throughout the text. Intermediate scales can estimate SWC over areas of 10 to $100,000 \mathrm{~m}^{2}$, using, for instance, GPR or electrical resistivity methods (Dabas et al., 2002), to areas of 1 to $100 \mathrm{~km}^{2}$, using aircraft remote sensing (Jackson et al., 1999).

LOCAL SCALE. Measurement at the local scale $\left(\approx 0.01 \mathrm{~m}^{2}\right)$ is performed with in situ measurement using sensors of different size and shape. The site Sowacs.com (Sowacs, 2010) provides a list of available commercial sensors for measuring SWC. As described above, among the most common devices for SWC measurement at this scale are the ones based on dielectric measurements. Comparative analyses of various sensors for measuring SWC were presented by Blonquist et al. (2005), Bogena et al. (2007), Evett et al. (2008), Inoue et al. (2008), Plauborg et al. (2005), and Robinson et al. (2003). One of the main advantages of using in situ sensor is that these sensors can be connected to dataloggers and automatically retrieve SWC data in real time and provide detailed time series (Bittelli et al., 2008).
Figure 1 depicts daily measurement of SWC at $10-\mathrm{cm}$ depth, in a small catchment in northern Idaho (Bittelli et al., 2010), determined with a reflectometer probe (model CS615; Campbell Scientific, Logan, UT). mative SWC time series at different depths, and they can be used to manage irrigation scheduling, compute the soil-water budget, corroborate soilplant models, and other applications.

Today, it is also possible to install distributed wireless sensor networks to obtain data in various locals across a field or a watershed (Brown et al., 2007). The current disadvantages are as follows: 1) sensor calibration is often needed for use in different soil types, 2) methodologies are not standardized, and 3) the SWC measurement is obtained only for very small soil areas (local measurement).

An important issue limiting the applicability of these sensors is the effect on the dielectric measurement of the dielectric losses occurring in saline and clay soils. For example, the main assumption behind the use of TDR is of negligible losses; therefore, assuming that only the real part of the dielectric permittivity determines the value of the TDR-measured apparent dielectric permittivity. This assumption is not valid for conductive soils (clay soils) or where high concentrations of electrolyte are present in the soil solution (saline soils) because, under these conditions, the contribution of the imaginary part is important. One of the main effects of dielectric losses on the TDR measurement is overestimation of SWC (Bittelli et al., 2008; Topp et al., 2000). More complex calibration equations were presented to address the issues of interferences from These sensors can provide very infor-

soil bulk EC and bound water related to soil temperature and clay content and type (e.g., Evett et al., 2005; Schwartz et al., 2009a, 2009b).

The spatial variability of SWC across a field is another important factor. One of the first researches analyzing the spatial and temporal variability of soil moisture was presented by Vachaud et al. (1985). In their work, they presented the concept of time stability. This concept describes that, for the same individual location, the SWC value maintain its rank in a cumulative probability function and its statistical parameters, for different sampling time. The rationale behind this concept is that, for similar vegetation conditions, the SWC depends on soil texture; therefore, this stability is based on the relationship between SWC and soil texture. Several improved estimation techniques have been developed based on the temporal stability concept, including the interpretation of measurements of SWC from microwave satellites (Wagner et al., 2008). One of the largest studies on the spatial and temporal variability of SWC was the Southern Great Plains 1997 (SGP97) study (Famiglietti et al., 1999). The authors showed variations in SWC depending on soil type, vegetation, and rainfall gradients. The statistical properties within fields (spatial variability) were related to the amount of SWC, with negatively skewed/nonnormal distribution under very wet conditions, normal in the midrange to positively skewed/nonnormal under dry conditions. Other authors investigated the dependence of statistical and geostatistical land properties to the SWC level (Entin et al., 2000; Hupet and Vanclooster, 2002).

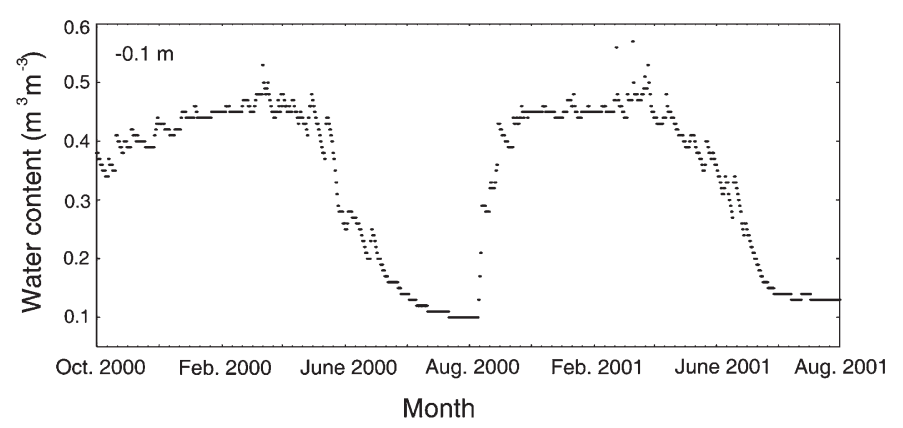

Fig. 1. Example of local-scale soil water content measurement performed with timedomain reflectometer at a depth of $0.1 \mathrm{~m}$ from Oct. 2000 to Aug. 2001, in a vertical profile for a watershed in northern Idaho (Bittelli et al., 2010). Note the typical seasonal cycle of soil water content; $1 \mathrm{~m}=3.2808 \mathrm{ft}, 1 \mathrm{~m}^{3}=35.3147 \mathrm{ft}^{3}$. 
FIELD SCALE. Estimation of SWC at the field scale may range from a few meters (10 to $50 \mathrm{~m}^{2}$ ) up to several hectares $\left(10,000\right.$ to $\left.100,000 \mathrm{~m}^{2}\right)$, and they are usually performed with geophysical methods such as GPR or electrical resistivity. GPR is a noninvasive technique that can detect subsurface structure and has been used to estimate SWC (Gerhards et al., 2008; Huisman et al., 2003). Figure 2 shows an increase in SWC after irrigation obtained using GPR ground wave and TDR measurements in a $60 \times 60$ $\mathrm{m}^{2}$ area and at a depth of $0.1 \mathrm{~m}$ (Huisman et al., 2003). Dabas et al. (2002) presented a system for fast mapping of electrical resistivity by using a motorized vehicle to map large areas and then deriving the SWC from soil EC.

Geophysical methods have the advantages of estimating SWC over areas that are much larger than the ones obtained from traditional local scale measurements and providing information for a few meters in depth. The disadvantages of geophysical methods is that they require regular field surveys to obtain information of SWC with time, whereas local and global scale techniques can provide automated acquisition, by either using automatic dataloggers (for in situ sensors) or periodic acquisition of satellite data. Moreover, the drawbacks of geophysical methods are commonly related to the difficulties of obtaining SWC from reflections measurements and the high cost of instrumentation such as GPR or resistivity methods.
Catchment scale. The catchment scale is the most problematic scale since it is between the local and field scale and the regional and global scale. Currently, numerous local-scale sensors may be installed to obtain a network of local data; however, this approach is not cost-effective and geographic range is limited.

Geophysical methods (resistivity and GPR) can map larger sections of the catchment in a less labor-intensive manner. Aircraft remote sensing may be employed for large catchments, using microwave sensors mounted on the plane. The spatial resolution of airborne data typically ranges from $50 \mathrm{~m}$ to $1 \mathrm{~km}$, while the SWC estimation can cover areas from 1 to $100 \mathrm{~km}^{2}$. This intermediate spatial scale can be used to bridge the gap between local and field scale measurements and satellite observations. Specifically, airborne data can be used to assess the models developed from ground-based data and develop parameterizations that include the subpixel surface heterogeneity. Indeed, modeling techniques are very important for supporting data interpretation and for addressing the many unresolved issues that still limit applications of SWC measurement at this scale (such as down- and upscaling techniques and analysis of spatial heterogeneities). Determination of SWC from airplanes and helicopters using microwave remote sensing was presented by Macelloni et al. (2002, 2003), with scattering coefficients used to determine soil moisture. Santi et al. (2009) presented a study where
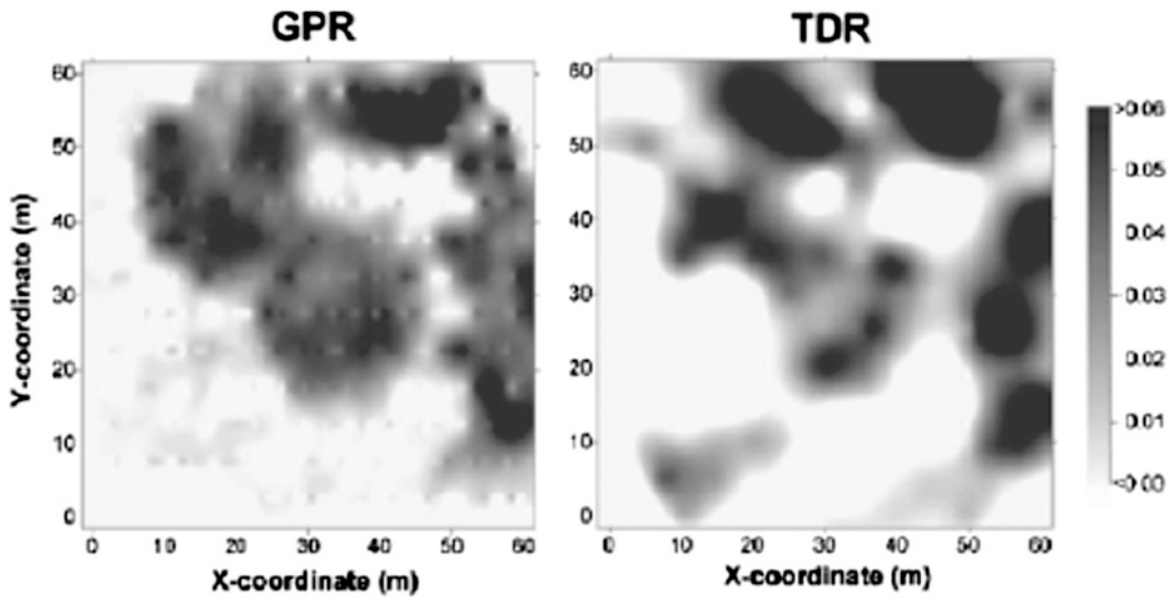

Fig. 2. Example of field-scale maps, representing soil water content measured with ground-penetrating radar (GPR) and multiple time-domain reflectometer (TDR) in a $60 \times 60 \mathrm{~m}^{2}$ area (from Huisman et al., 2003); $1 \mathrm{~m}=3.2808 \mathrm{ft}$. an airborne campaign with multifrequency microwave radiometers at $\mathrm{L}, \mathrm{C}$, and $\mathrm{X}$ bands was carried out on a flat alluvial area in northern Italy, in the Po Valley, with the aim of improving the estimation of airborne soil moisture and vegetation biomass maps, using both active and passive sensors. Ground measurements performed with TDR were used for testing and comparison of SWC data against the airborne data. Figure 3 shows an example of flight lines for the study of Santi et al. (2009), performed to measure brightness temperature from which estimation of SWC was obtained. Other studies on SWC determination from L-band and IR sensors from airplanes were presented by Merlin et al. (2008) and Teuling et al. (2007).

Regional and global scale. Since the 1970s, various methods have been proposed for remote sensing of SWC, including visible and thermal space-borne data (Verstraeten et al., 2006) and microwave remote sensing (Njoku et al., 2003). Microwave remote sensing using satellites has become the primary remote sensing technique for measurement of SWC at the regional and global scale.

Microwave instruments are well suited for soil moisture retrieval because of the strong relationship between dielectric permittivity and soil moisture. Moreover, microwave remote sensing is not significantly affected by cloud cover and is able to penetrate (to some extent) vegetation and soil while maintaining sensitivity to SWC. The sensors can be divided in two categories: passive sensors and active sensors. Passive sensors (radiometers) detect radiation emitted by the earth's surface, whereas active sensors (radars) transmit an electromagnetic wave to the target and measure the reflected or scattered energy back to the sensor.

Radiometers measure the brightness temperature, which is affected by soil, vegetation, snow cover, surface roughness, and atmosphere (Njoku et al., 2003; Schmugge, 1998). Since the early 1990s, a variety of satellites equipped with radiometers have been lunched, including the Scanning Multichannel Microwave Radiometer (SMMR) on the Nimbus-7 satellite, the Tropical Rainfall Measuring Mission (TRMM), and the Advanced Microwave Scanning Radiometer 


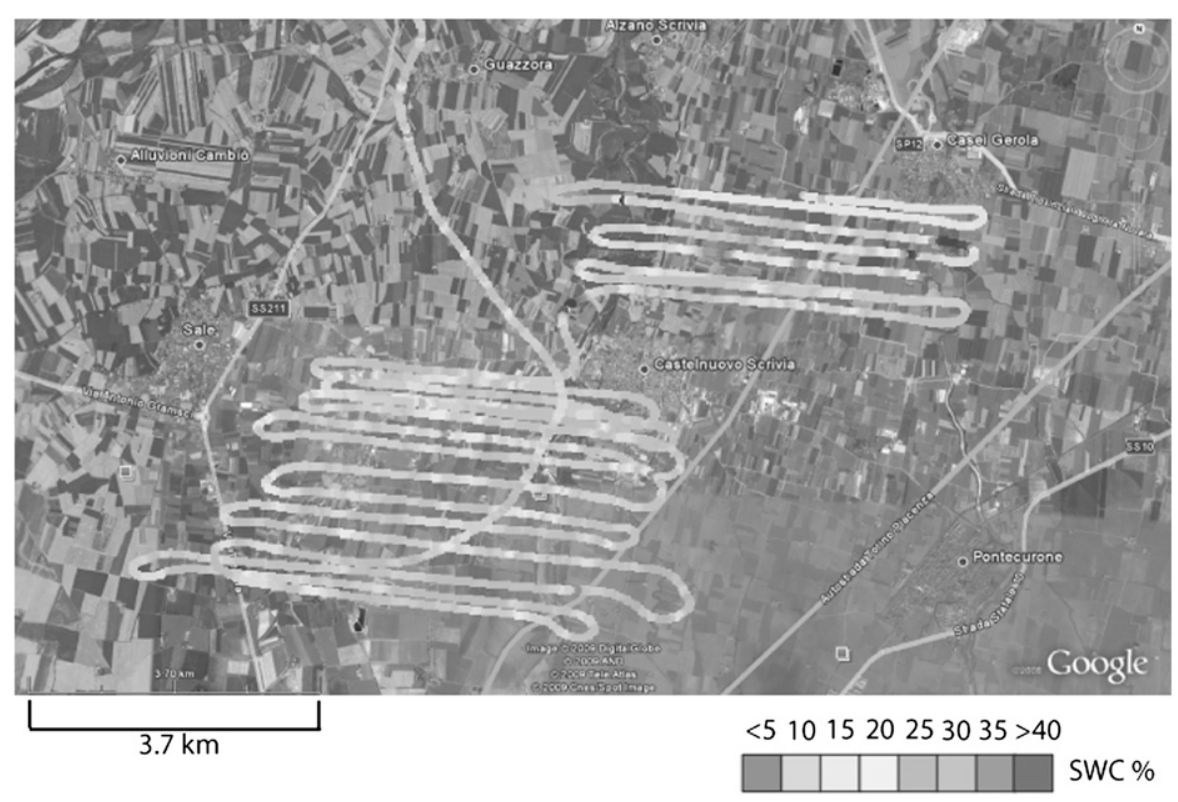

Fig. 3. Example of geo-referenced flight lines performed by the aircraft to measure brightness temperature. The site selected for performing the experiments was a flat agricultural area close to Alessandria, northern Italy (central coordinates: lat. $45^{\circ} \mathrm{N}$, long. $\left.8.5^{\circ} \mathrm{E}\right)$, a flat alluvial plain measuring $\approx 300 \mathrm{~km}^{2}\left(115.8 \mathrm{miles}^{2}\right)$. Colors correspond to soil water content (SWC) values obtained from brightness temperature [courtesy of S. Paloscia (from Santi et al., 2009)]; $1 \mathrm{~km}=0.6214 \mathrm{mile}$.

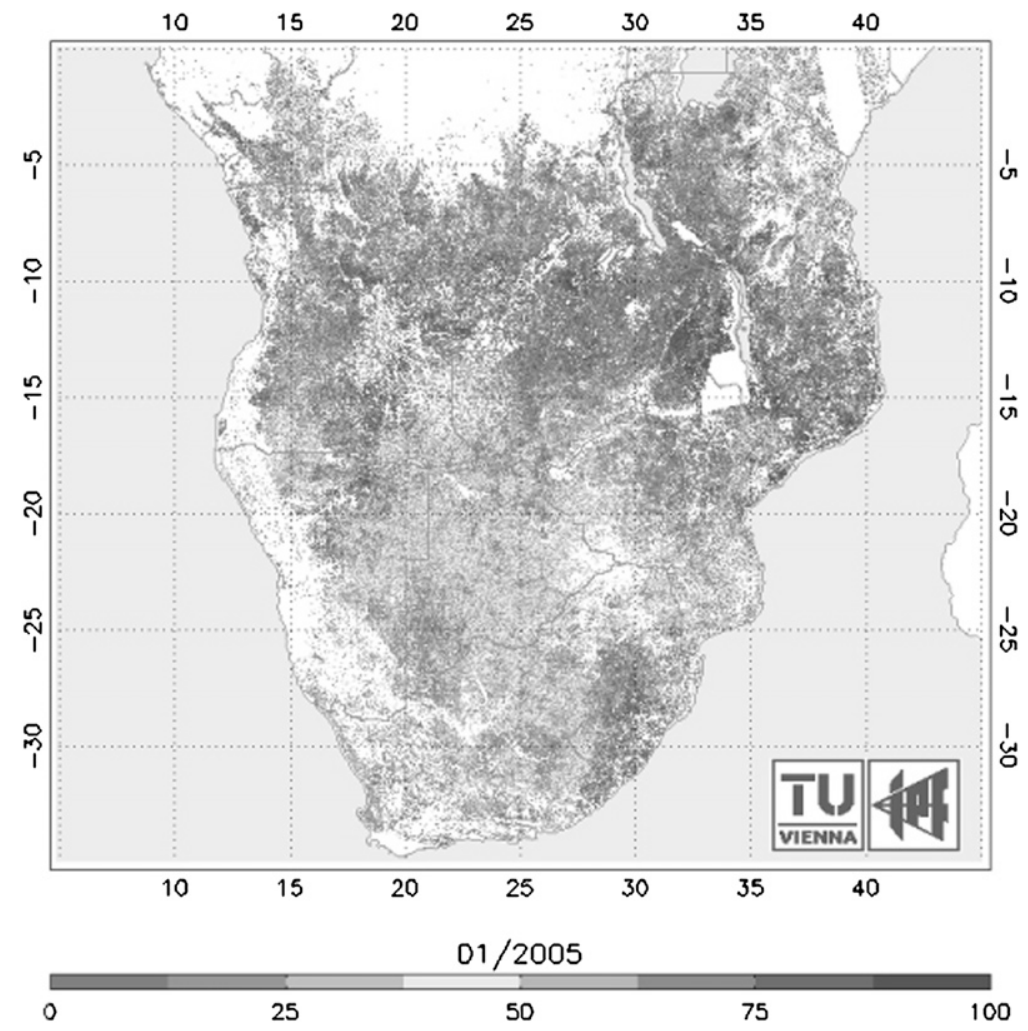

Fig. 4. Example of regional-scale-estimated soil water content using advanced synthetic aperture radar operating at C-band in Africa, Jan. 2005. A global grid with a sampling interval of 15 arc seconds, corresponding to a distance of $\approx 500 \mathrm{~m}$ $(1640.4 \mathrm{ft})$ at the equator, was defined. The chosen datum is WGS-84 with the origin set to lat. $90^{\circ} \mathrm{S}$, long. $180^{\circ} \mathrm{W}$ (Wagner et al., 2007b).
(AMSR)-Earth Observing System (EOS) on board of the National Aeronautics and Space Administration (NASA) satellite, Aqua (Njoku et al., 2003).

There are primarily two types of radar currently being used for SWC retrieval: synthetic aperture radar (SAR) and scatterometers. SAR is coherent radar, where high resolution images are created from the backscatter signals. Currently, the European Space Agency (ESA) is using the Earth Remote Sensing (ERS-1 and ERS-2) satellites for SWC remote sensing (Wagner et al., 2003, 2007a). Scatterometers are microwave radar sensors that measure the normalized radar cross section of the surface, scanned from an airplane or a satellite (Dubois et al., 1995; Schmugge, 1998; Wagner and Scipal, 2000). They were primarily developed for measurement of nearsurface winds over the ocean, based on the fact that wind determines smallscale changes of the sea surface, affecting the sea-surface roughness and, therefore, the backscattering properties. In addition to their original purpose, scatterometers are now also being used for polar ice studies, vegetation coverage, and SWC measurements. A variety of scatterometers have been launched on board satellites, such as the NASA scatterometer (NSCAT) and the sensor advanced scatterometer (ASCAT) on board of the ESA meteorological operational satellite (MetOp-A) launched in 2006 (Wagner et al., 2003, 2007a).

Scatterometers have the advantage of being active during day and night time and to be unaffected by cloud coverage, providing aroundthe-clock coverage. Commonly, the scattering coefficients measured from the sensors are used as input for physical models to derive specific properties of the surface (Jarlan et al., 2002; Zine et al., 2005). However, physical models can often be difficult to parameterize, so simpler moisture retrieval methods have been presented, such as those based on change detection (Wagner et al., 1999), where SWC is computed based on differences over long-term computation between the lowest and the highest value of backscatter. One of the disadvantages of the microwave sensors in general is the coarse spatial resolution, which is 50 and $25 \mathrm{~km}$, depending on the sensors. However, recent studies have 
developed downscaling procedures on the basis of the combination of SAR and ASCAT data (Wagner et al., 2008), which allowed to downscale the data to a $1-\mathrm{km}$ spatial resolution.

Figure 4 shows an example of 1-km experimental SWC over Africa for Jan. 2005 (Wagner et al., 2007b). Another limitation of satellite microwave remote sensing is that the soil penetration depth (at frequencies between 1 and $2 \mathrm{GHz}$ ) is $\approx 5 \mathrm{~cm}$. Therefore, various soil-water-budget models are used to obtain information at deeper depths, for instance, for plant available water.

However, further studies on effective down- and upscaling techniques, as well as large-scale modeling, are necessary for obtaining reliable SWC estimates and for inferring the shallow information obtained by satellites to deeper soil depths. These issues are still a challenge because of the complexity of obtaining soil hydraulic properties over very large areas and the need for simplified models that can be applied at the regional and global scale (Pistocchi et al., 2008).

\section{Current challenges and future research}

- Accuracy of in situ measurement with dielectric sensors in saline and clay soil is still problematic although some experimental and theoretical approaches have been presented to address this issue.

- Uncertainty in SWC measurement, associated with in situ measurements for different local-scale sensors, still needs to be investigated although some comparative studies have been performed as described above.

- Identification of the best techniques for SWC measurement at the catchment scale and compatibility with the grid sizes used in catchment-scale hydrological modeling is necessary.

- Integration of information at different scales remains one of the primary challenges, especially theidentification of efficient techniques for downscaling of satellite data.

- Simplified large-scale SWC modeling (regional and global scale) is necessary and still a challenge because of the complexity of acquiring knowledge of soil hydraulic properties necessary for correct modeling.

- Several new techniques, including optical and gravity measurements, are in the process of being developed and merit additional research.

\section{Literature cited}

Adamo, F., G. Andria, F. Attivissimo, and N. Gianquinto. 2004. An acoustic method for soil moisture measurement. Inst. Electrical Electronics Eng., Trans. Instrumentation Measurement 53:891-898.

Amer, S.A., T.O. Keefer, M.A. Weltz, D.C. Goodrich, and L.B. Bach. 1994. Soil moisture sensors for continuous monitoring. Water Resources Bul. 30:69-83.

Bittelli, M., F. Salvatorelli, and P. Rossi Pisa. 2008. Correction of TDR-based soil water content measurements in conductive soils. Geoderma 143:133-142.

Bittelli, M., F. Tomei, A. Pistocchi, M. Flury, J. Boll, E.S. Brooks, and G. Antolini. 2010. Development and testing of a physically based, three-dimensional model of surface and subsurface hydrology. Adv. Water Resources 33:106-122.

Blonquist, J.M., S.B. Jones, and D.A. Robinson. 2005. Standardizing characterization of electromagnetic water content sensors: Part 2. Evaluation of seven sensing systems. Vadose Zone J. 4:10591069 .

Blum, A., I. Flammer, T. Friedli, and P. Germann. 2004. Acoustic tomography applied to water flow in unsaturated soils. Vadose Zone J. 3:288-299.

Bogena, H.R., J.A. Huisman, C. Oberdörster, and H. Vereecken. 2007. Evaluation of a low-cost soil water content sensor for wireless network applications. J. Hydrol. (Amst.) 344:32-42.

Brown, D.J., J.C. Crupper, C.S. Campbell, D.R. Cobos, C.A. Perillo, and D.R Huggins. 2007. Constructing a field-scale dynamic landscape model of soil hydrology using data from a distributed wireless sensor network. Amer. Soc. Agron, Crop Sci. Soc. Amer., Soil Sci. Soc. Amer. Annu. Mtg, New Orleans, LA. p. 301302. (abstr.).

Dabas, M. 2006. La prospection géophysique, p. 167-216. In: A. Ferdière, M. Dabas, H. Delétang, A. Ferdière, C. Jung, and W. Haio Zimmermann. La prospection. Collection archéologiques, Edition Errance, Paris.

Dabas, M. 2009. Theory and practice of the new fast electrical imaging system ARP, p. 105-126. In: S. Campana, and S. Piro (eds.). Seeing the unseen. Taylor \& Francis, London.

Dabas, M., C. Perrard, A. Favard, and D. Rouiller. 2002. A new system for fast mapping of ER (A.R.P.): Field application.
Proc. 6th Intl. Conf. Precision Agriculture and Other Precision Resources Management. Minneapolis, MN. p. 121-129.

Dubois, P.C., J. van Zyl, and T. Engman. 1995. Measuring soil moisture with imaging radar. IEEE Trans. Geosci. Rem. Sens. 33:915-926.

Entin, J.K., A. Robock, K.Y. Vinnikov, S.E. Hollinger, S. Liu, and A. Namkhai. 2000. Temporal and spatial scales of observed soil moisture variations in the extratropics. J. Geophys. Res. 105:11865-11877.

Evett, S.R. 2008. Neutron moisture meters, p. 39-54. In: S.R. Evett, L.K. Heng, P. Moutonnet and M.L. Nguyen (eds.). Field estimation of soil water content: A practical guide to methods, instrumentation, and sensor technology. IAEA-TCS30. International Atomic Energy Agency, Vienna, Austria.

Evett, S.R. and G.W. Parkin. 2005. The continuing maturation of technology and theory. Vadose Zone J. 4:986-991.

Evett, S.R., J.A. Tolk, and T.A. Howell. 2005. TDR laboratory calibration in travel time, bulk electrical conductivity, and effective frequency. Vadose Zone J. 4:1020-1029.

Evett, S.R., L.K. Heng, P. Moutonnet, and M.L. Nguyen. 2008. p. 123-129. In: S.R. Evett, L.K. Heng, P. Moutonnet, and M.L. Nguyen (eds.). Field estimation of soil water content: A practical guide to methods, instrumentation, and sensor technology. IAEA-TCS-30. Intl. Atomic Energy Agency, Vienna, Austria.

Evett, S.R., R.C. Schwartz, J.A. Tolk, and T.A. Howell. 2009. Soil profile water content determination: Spatiotemporal variability of electromagnetic and neutron probe sensors in access tubes. Vadose Zone J. 8:926-941.

Famiglietti, J.S., J.A. Devereaux, C.A. Laymon, T. Tsegaye, P.R. Houser, T.J. Jackson, S.T. Graham, M. Rondell, and P.J. van Oevelen. 1999. Ground-based investigation of soil moisture variability within remote sensing footprints during the Southern Great Plains (1997) Hydrology Experiment. Water Resources Res. 35:1839-1851.

Ferré, P.A., D.L. Rudolph, and R.G. Kachanosky. 1996. Spatial averaging of water content by time domain reflectometry: Implications for twin rod probes with and without dielectric coatings. Water Resources Res. 33:1455-1460.

Gardner, C.M.K., T.J. Dean, and J.D. Cooper. 1998. Soil moisture measurement with a high frequency capacitance sensor. J. Agr. Eng. Res. 71:395-403.

Gerhards, H., U. Wollschläger, Q. Yu, P. Schiwek, X. Pan, and K. Roth. 2008. 
Continuous and simultaneous measurement of reflector depth and average soil-water content with multichannel groundpenetrating radar. Geophysics 73:j15-j23.

Hallikainen, M.T., F.T. Ulaby, M.C. Dobson, M.A. El-Rayes, and L.K. Wu. 1985. Microwave dielectric behavior of wet soil-part 1: Empirical models and experimental observations. Inst. Electrical Electronics Eng. Trans. Geoscience Remote Sensing 23:25-34.

Hignett, C. and S.R. Evett. 2002. Neutron thermalization, p. 501-521. In: J.H. Dane and G.C. Topp (eds.). Methods of soil analysis. Part 4-Physical methods. Amer. Soc. Agron., Madison, WI.

Huisman, J.A., S.S. Hubbard, J.D. Redman, and A.P. Annan. 2003. Measuring soil water content with ground penetrating radar: A review. Vadose Zone J. 2:476-491.

Hupet, F. and M. Vanclooster. 2002. Intraseasonal dynamics of soil moisture variability within a small agricultural maize cropped field. J. Hydrol. (Amst.) 261:86-101.

Inoue, M., B.A. Ould Ahmed, T. Saito, and M. Irshad. 2008. Comparison of twelve dielectric moisture probes for soil water measurement under saline conditions. Amer. J. Environ. Sci. 4:367-372.

Jackson, T.J., D.M. Le Vine, A.Y. Hsu, A. Oldak, P.J. Starks, C.T. Swift, J.D. Isham, and M. Haken. 1999. Soil moisture mapping at regional scales using microwave radiometry: The Southern Great Plains Hydrology Experiment. Inst. Electrical Electronics Eng. Trans. Geoscience Remote Sensing 37:2136-2151.

Jarlan, L., E. Mougin, P.L. Frison, P. Mazzeg, and P. Hiernaux. 2002. Analysis of ERS wind scatterometer time series over Sahel (Mali). Remote Sens. Environ. 81:404-415.

Leiriao, S., X. He, L. Christiansen, O.B. Andersen, and P. Bauer-Gottwein. 2009. Calculation of the temporal gravity variation from spatially variable water storage change in soils and aquifers. J. Hydrol. (Amst.) 365:302-309.

Lu, Z. 2007. The phase shift method for studying nonlinear acoustics in a soil. Acta Acustica United 93:542-554.

Macelloni, G., S. Paloscia, P. Pampaloni, R. Ruisi, M. Dechambre, R. Valentin, A. Chanzy, and J.P. Wigneron. 2002. Active and passive microwave measurements for the characterization of soils and crops. Agronomie 22:581-586.

Macelloni, G., S. Paloscia, P. Pampaloni, E. Santi, and M. Tedesco. 2003. Microwave radiometric measurements of soil moisture in hilly regions in Italy. Hydrol. Earth Syst. Sci. 7(6):1-12.
Merlin, O., J.P. Walker, J.D. Kalma, E. Kim, J. Hacker, R. Panciera, R. Young, G. Summerell, J. Hornbuckle, M. Hafeez, and T. Jackson. 2008. The NAFE'06 data set: Towards soil moisture retrieval at intermediate resolution. Adv. Water Resources 31:1444-1455.

Njoku, E.G., T.J. Jackson, V. Lakshmi, T.K. Chan, and S.V. Nghiem. 2003. Soil moisture retrieval from AMSR-E. Inst. Electrical Electronics Eng. Trans. Geoscience Remote Sensing 41:215-229.

Pistocchi, A., F. Bouraoui, and M. Bittelli. 2008. A simplified parameterization of the monthly topsoil water budget. Water Resources Res. W12440: doi: 10.1029/ 2007WR006603.

Plauborg, F., B.V. Iversen, and P.E. Laerke. 2005. In situ comparison of three dielectric soil moisture sensors in drip irrigated sandy soils. Vadose Zone J. 4:1037-1047.

Reece, C.F. 1996. Evaluation of a line heat dissipation sensor for measuring soil matric potential. Soil Sci. Soc. Amer. J. 60:1022-1028.

Robinson, D.A., C.M.K. Gardner, and J.D. Cooper. 1999. Measurement of relative permittivity in sandy soils using TDR, capacitance and theta probes: Comparison, including the effects of bulk soil electrical conductivity. J. Hydrol. (Amst.) 223:198-211.

Robinson, D.A., S.B. Jones, J.A. Wraith, D. Or, and S.P. Friedman. 2003. A review of advances in dielectric and electrical conductivity measurement in soils using time domain reflectometry. Vadose Zone J. 2:444-475.

Roth, K., R. Schulin, H. Flühler, and W. Attinger. 1990. Calibration of time domain reflectometry for water content measurement using a composite dielectric approach. Water Resources Res. 26:22672273.

Samouelian, A., I. Cousin, A. Tabbagh, A. Bruand, and G. Richard. 2005. Electrical resistivity survey in soil science: A review. Soil Tillage Res. 83:173-193.

Santi, E., S. Paloscia, P. Pampaloni, S. Pettinato, and M. Brogioni. 2009. Airborne microwave radiometric measurements of soil moisture and comparison with SAR data. Proc. Geoscience Remote Sensing Symp., IGARSS 2009, Institute of Electrical and Electronics Engineers. p. 937-940.

Schmugge, T. 1998. Applications of passive microwave observations of surface soil moisture. J. Hydrol. (Amst.) 212/213: 188-197.

Schwartz, R.C., S.R. Evett, and J.M. Bell. 2009a. Complex permittivity model for time domain reflectometry soil water content sensing. II. Calibration. Soil Sci. Soc. Amer. J. 73:898-909.

Schwartz, R.C., S.R. Evett, M.G. Pelletier, and J.M. Bell. 2009b. Complex permittivity model for time domain reflectometry soil water content sensing. I. Theory. Soil Sci. Soc. Amer. J. 73:886-897.

Selker, J., N. van de Giessen, M. Westhoff, W. Luxemburg, and M.B. Parlange. 2005. Fiber optics opens window on stream dynamics. Geophys. Res. Lett. 33:L24401.

Seyfried, M.S. 1993. Field calibration and monitoring of soil-water with fiberglass electrical resistance sensors. Soil Sci. Soc. Amer. J. 57:1432-1436.

Shiozawa, S. and G.S. Campbell. 1990. Soil thermal conductivity. Rem. Sens. Rev. 5:301-310.

Sowacs. 2010. sowacs.com: The central resource for soil moisture measurement. 18 Oct. $2010 .<$ http://www.sowacs.com/ index.html>.

Teuling, A.J., R. Uijlenhoet, R. Hurkmans, O. Merlin, R. Panciera, J.P. Walker, and P.A. Troch. 2007. Dry-end surface soil moisture variability dynamics during NAFE'06. Geophys. Res. Lett. 34:doi: 10.1029/ 207GL031001

Tidwell, V.C. and R.J. Glass. 1994. X-ray and visible-light transmission for laboratory measurement of 2-dimensional saturation fields in thin-slab systems. Water Resources Res. 30:2873-2882.

Topp, G.C., J.L. Annan, and A.P. Davis. 1980. Electromagnetic determination of soil water content: Measurements in coaxial transmission lines. Water Resources Res. 16:574-582.

Topp, G.C., S. Zegelin, and I. White. 2000. Impacts of the real and the imaginary components of relative dielectric permittivity on time domain reflectometry measurements in soils. Soil Sci. Soc. Amer. J. 64:1244-1252.

Vachaud, G., A. Passerat de Silans, P. Balabanis, and M. Vauclin. 1985. Temporal stability of spatially measured soil water probability density function. Soil Sci. Soc. Amer. J. 49:822-828.

Verstraeten, W.W., F. Veroustraete, C.J. van der Sande, I. Grootaers, and J. Feyen. 2006. Soil moisture retrieval using thermal inertia, determined with visible and thermal spaceborne data, validated for European forests. Remote Sens. Environ. 101:299-314

Wagner, W., G. Lemoine, and H. Rott. 1999. A method for estimating soil moisture from ERS scatterometer and soil data. Remote Sens. Environ. 70:191207. 


\section{WORKSHOP}

Wagner, W., C. Pathe, M. Doubkova, D. Sabel, A. Bartsch, S. Hasenauer, G. Bloschl, K. Scipal, J.M. Fernzandez, and A. Low. 2008. Temporal stability of soil moisture and radar backscatter observed by the Advanced Aperture Radar (ASAR). Sensors (Basel Switzerland) 8:1174-1197.

Wagner, W. and K. Scipal. 2000. Largescale soil moisture mapping in western Africa using the ERS scatterometer. IEEE Trans. Geosci. Rem. Sens. 38:17771782.

Wagner, W., K. Scipal, C. Pathe, D. Gerten, W. Lucht, and B. Rudolf. 2003. Evaluation of the agreement between the first global remotely sensed soil moisture data with model and precipitation data. J. Geophysical Res. Atmospheres 108:46114615.
Wagner, W., V. Naeimi, K. Scipal, R. de Jeu, and J. Martínez-Fernández. 2007a. Soil moisture from operational meteorological satellites. Hydrogeol. J. 15:121-131.

Wagner, W., C. Pathe, D. Sabel, A. Bartsch, C. Künzer, and K. Scipal. 2007b. Experimental $1 \mathrm{~km}$ soil moisture products from ENVISATASAR for southern Africa, Proc. 'Envisat Symp. 2007', Montreux, Switzerland, 23-27 Apr. 2007. p. 133-143.

Walker, J.P. and P.R. Houser. 2002. Evaluation of the ohmmapper instrument for soil moisture measurement. Soil Sci. Soc. Amer. J. 66:728-734.

Wenner, F. 1915. A method of measuring earth resistivity. U.S. Bur. Stnd. Bul. 12: 469-478.
Wraith, J.M. and D. Or. 1999. Temperature effects on soil bulk dielectric permittivity measured by time domain reflectometry: Experimental evidence and hypothesis development. Water Resources Res. 35: 361-369.

Young, M.H., G.S. Campbell, and J. Yin. 2008. Correcting dual-probe heat-pulse readings for changes in ambient temperature. Vadose Zone J. 7:22-30.

Zine, S., L. Jarlan, P.-L. Frison, E. Mougin, P. Hiernaux, and J.-P. Rudant. 2005. Land surface parameter monitoring with ERS scatterometer data over the Sahel: A comparison between agro-pastoral and pastoral areas. Remote Sens. Environ. 96:438-444. 